\title{
Virtual campus designing and planning
}

\author{
Liu li-zhen \\ Wenzhou Vocational \& Technical College, Wenzhou. 325035 \\ Xia441@sina.com
}

Keywords: 3D Rhino; modeling; Google Earth; dummyschool

\begin{abstract}
With expanding admissions in every college in our country this recent years,future education is changing forn elite to popular. Students and parents pay more and more attention in school'location. environment and other conditions, but some colleges are too far away form home for field observation, so they had to get some unintuition information about school form traditional 2D web pages ,now Virtual Campus if used with corresponding explain can work out this problem very well, and it can observe school in 360 degree comprehensivity.

Virtual Campus's design applied computer's3D modeling method and internet informations, through computer shows the campus humanities and campus style and features, 3D Rhino is a classical "NURBS" software. It makes up surfaces rely on points and lines, and then makes up the basic grapes we need, it can establishes complex model conveniently and fastly the author select 3D Rhino as develop software make innovation study and realize in Virtual Campus.

This passage introduces how to use 3D Rhino and Coogle SketchUP to make virtual school scenes, school's 3D scene model's making and narratives how to visit virtual campus through Google Earth ,the major content can divided into three parts.

First: Study how to establish college surface 3D building's outside scenes model ingreat detail through remote sensing satellites pictures and inside seenes shooting means get scenes datas, use 3DRhino modeling skill establish scene models.3DRhino can build complex surface effects, such as school's sculptures\roofs\complex fences and walls' scenes models.

Second: Take Google SketchUP map measure make materials map into models to get lifelike 3D sculpture, use Google SketchUP's truly grain or get form take photos add to model surface, Delete useless buildings details to optimization dealing with models, to prominent the features about buildings.

With the advent of the Internet age , today, the computer has been deeply every family.Many famous universities such as Zhejiang University, Shanghai Jiaotong University, etc., adopting virtual reality technology to build a virtual campus. Virtual campus provides a platform ,which to help achieve the University 's resource management, environmental planning and school development, remote access, etc.In today's changing the technology will be applied to more schools with eelectronic information technology(Electronics IT) improve.

In most of the campus network has been widely used, with the development of colleges and universities in our country, the improvement of the education system, more and more students have the opportunity to enter colleges and universities for further study. Many colleges and universities have to start expansion.Based on a series of teaching, accommodation and other facilities continue to increase, the effective management of the campus began to be taken seriously.Therefore, campus information management has become the most effective management.Most schools began to use the network to establish their own teaching, living, entertainment and other systems.And compared to traditional campus, virtual campus can give students a more intuitive, more effective understanding, so this technology has also vigorously developed in China.

During the globalization of information, the virtual campus created the conditions for the country 's schools to the world.Online virtual campus provides many opportunities not only for Chinese students but also for foreign students to to understand each other's university , college life, and even the campus culture .Through virtual campus, schools can have a more in-depth exchanges and contacts, which not only promotes academic exchanges, but also provides favorable conditions for enhancing the competitiveness of schools and optimizing Campus.
\end{abstract}


Image-based modeling techniques to draw the photo images of buildings, based on a large number of environmental stresses multi-angle photos into the computer for analysis, using computer vision technology to help analyze and establish the geometry of buildings and the environment.This method does not have to establish a separate complex model to analyze automatically by a computer model, if the technology is mature , will greatly enhance the efficiency of the building modeling .In recent years, this modeling approach concern of many scholars, and is committed to improving the technology and the popularity of talk .But now computer vision technology is not mature enough, modeled by this method still requires producers to enter a lot of matching data.How to achieve between the face image matching, how to eliminate or reduce the image noise , also remains to be further studied.Image-based modeling method flow chart shown in Figure 1 .

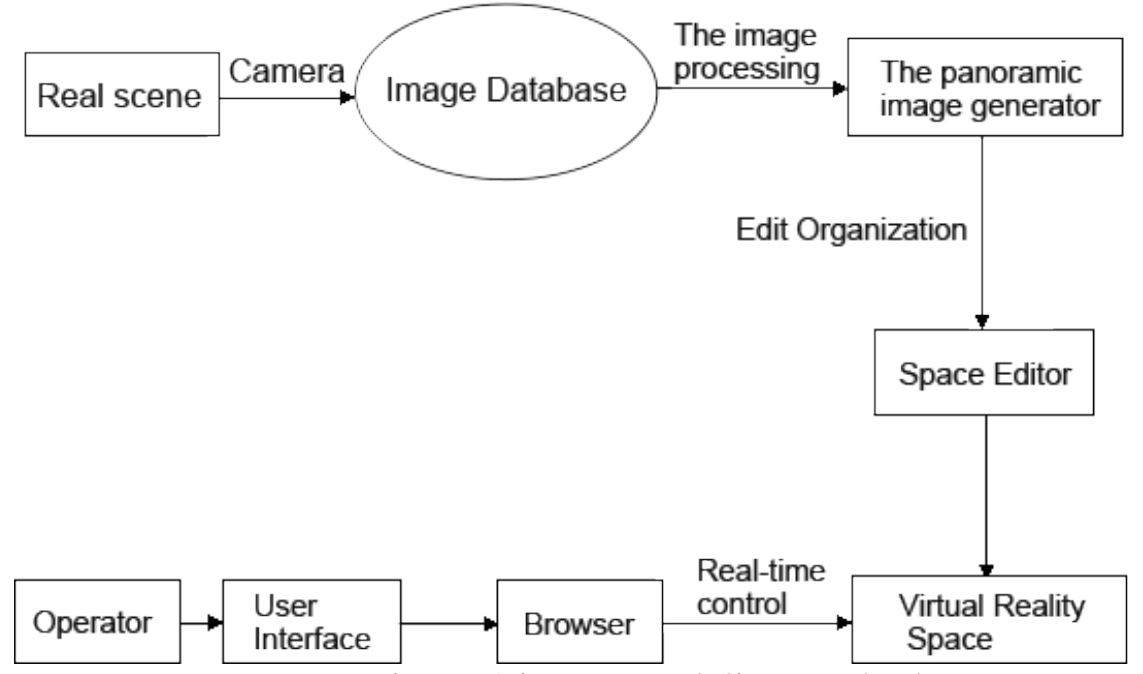

Figure 1 image modeling method

\section{Virtual Campus Problems}

With the popularization of network technology and google, more and more universities have begun to build their own virtual campus .From a functional point of view, the virtual campus is divided into two categories:

One virtual campus is mainly used to serve the campus teaching and management,and it is through the establishment of digital campus to expand the campus network functions;The other is mainly to show the campus scenery and school style, while making an inquiry and guided tours .

Technically,no matter what type of virtual campuses are using virtual reality technology to show more intuitive campus buildings and scenery.But as we can see ,there are still many shortcomings in the virtual campus technology ,mainly in the interaction between the viewer and the navigation is not good enough .That there are many problems to solve and improve the process of building a virtual campus, mainly in the following aspects:

1.1 At present, virtual campus mainly adopts three-dimensional(3D) panoramic way fixed-point observation, it can not be close observation, unable to see the scenes details.In order to maximize the display of three-dimensional(3D) scenes, its pre- image acquisition makes high demands .

1.2After a three-dimensional(3D) construction, virtual campus scenes are rendered into an image to be displayed. When a user browsing ,it only for fixed-point observation and not at liberty to browse ,, and it is more passive in terms of information inquiry, interaction is also poor.

1.3Realistic virtual campus scenes need to build a large geometric model, which is bound to take up a lot of storage space, the attendant problems is the browser opens the page in the network will take a long time .Therefore, a need to study the optimization method, making the model more realistic and less storage space on a balance can be achieved in improving the network transmission speed and fidelity scene coordination in hand, which in the future development of the virtual campus has very far-reaching significance.

Virtual campus landscape model according to the theory of cognitive research, geographical scope of the performance of the spatial objects within the scope encompasses part of the campus .In 
general, the phenomenon of these spaces can be divided into five types:geomorphology, architecture, transportation, public class facilities, green plants.As shown in Figure 2 .

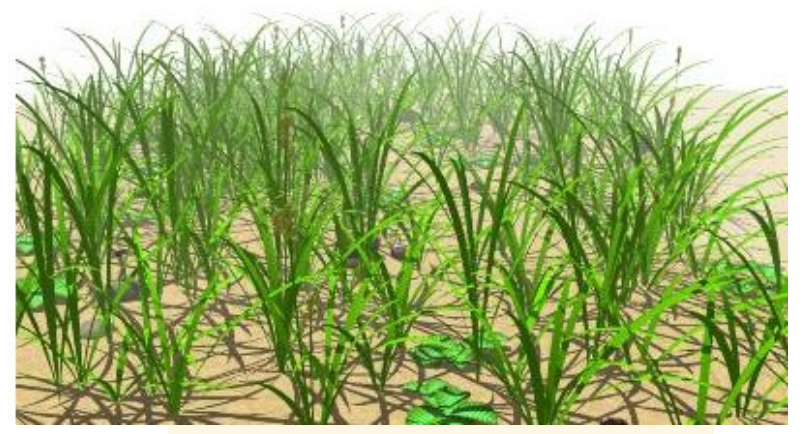

Figure 2 Low green vegetation

\section{Virtual campus data acquisition}

Data source virtual campus to obtain a three-dimensional model of the main source of long-range satellite imagery and close- range photogrammetry , shown in Figure 3 .

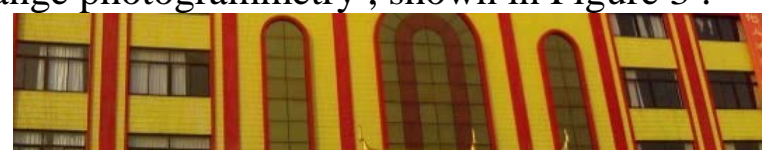

Figure 3 teaching building close range photogrammetry

The route guidance features virtual campus also can be widely applied .For example, clicking on your campus figure out what your location , and then enter the name of the building you want to go,can be shown in the drawing to help an optimal path to the destination.Not only can establish a virtual campus in the ground and it can also create a three-dimensional model of the earth, so that we can have a direct understanding of the building to quantify, but also through the establishment of underground pipelines, underground when needed to work through the virtual campus can accurately found in the pipeline space location, so that not only improve work efficiency, and can avoid hitting the important piped water, electricity, gas, etc. in the mining process, to avoid unnecessary losses.As shown in Figure 4 underground pipes virtual campus .

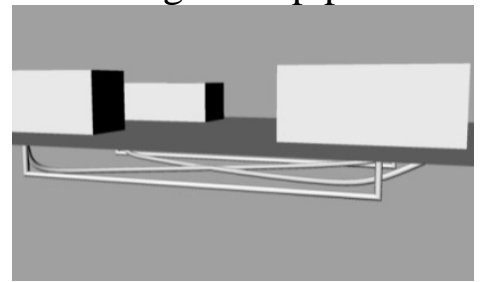

Figure 4 virtual campus underground pipes

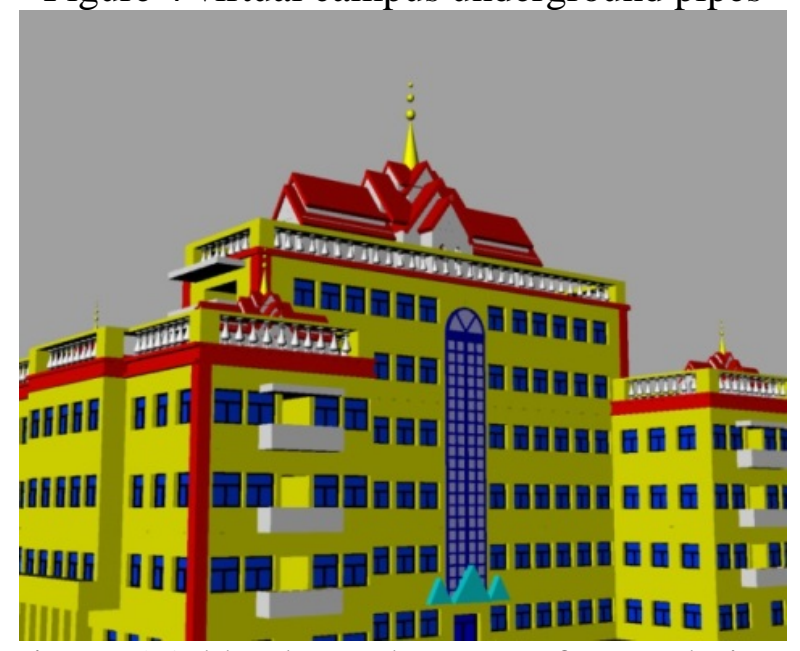

Figure 5 Add color and texture after renderings

After the House of campus built, the need for final integration as shown in Figure 5 .Model has 
been established by using the SU placed in planned topographic map position, Now the model needs to be created with the 3D Rhino imported into the SU .

3D Rhino model needs to establish export and save as 3ds file format, so you can import SU in the final model positioning.

\section{References}

[1] Zhiliang Xia. Application of reverse engineering based on computer in product [J] . International Journal of Multimedia and Ubiquitous Engineering, 2014,9(5); 343-354

[2] Xu RenPingge packaging new material and new technology [M]. Beijing: chemical industry press, 2006, 6

[3] Demaeztu L,Villanueva A,Cabeza R. Stereo matching using gradient similarity and locally adaptive support-weight[J].Pattern Recognition Letters,2011,32(13):1643-1651.

[4] Du Yiwei. China image element in the research of [J] enhancing the independent brand image. Beijing: decoration, 2008 (12). 